\title{
Article
}

\section{A Validation Procedure for Ecological Corridor Locations}

\author{
Etienne Lalechère * (D) and Laurent Bergès $(\mathbb{D}$ \\ Université Grenoble Alpes, INRAE, LESSEM, 38402 Saint-Martin-d'Hères, France; laurent.berges@inrae.fr \\ * Correspondence: lalechereetienne@gmail.com
}

\begin{abstract}
Connectivity conservation analysis is based on a wide range of approaches designed to pinpoint key ecological corridors in order to maintain multispecies flows. However, the lack of validation procedures with accessible data prevents one from evaluating the accuracy of ecological corridor locations. We propose a new validation procedure to evaluate the accuracy of ecological corridor locations in landscape connectivity approaches. The ability of the procedure to properly rank the accuracy of different landscape connectivity approaches was illustrated in a study case. Maxent model and circuit theory were used to locate ecological corridors for forest bird species, following three approaches based on land cover, umbrella species and multispecies presence data. The validation procedure was used to compare the three approaches. Our validation procedure ranked the three approaches as expected, considering that accuracy in locating ecological corridors is related to the biological realism of calibration data. The corridors modelled were more accurate with species presence data (umbrella and multispecies approaches) compared to land cover proxy (habitatbased approach). These results confirm the quality of the validation procedure. Our validation procedure can be used to: (1) evaluate the accuracy of the location of ecological corridors; (2) select the best approach to locate ecological corridors, and (3) validate the underlying assumptions of landscape connectivity approaches (e.g., dispersal and matrix resistance values).
\end{abstract}

Citation: Lalechère, E.; Bergès, L. A Validation Procedure for Ecological Corridor Locations. Land 2021, 10, 1320. https://doi.org/10.3390/ land10121320

Academic Editors: Monika Kopecká, Carlos T. López De Pablo and Andreu Bonet-Jornet

Received: 5 November 2021

Accepted: 29 November 2021

Published: 1 December 2021

Publisher's Note: MDPI stays neutral with regard to jurisdictional claims in published maps and institutional affiliations.

Copyright: (C) 2021 by the authors. Licensee MDPI, Basel, Switzerland. This article is an open access article distributed under the terms and conditions of the Creative Commons Attribution (CC BY) license (https:/ / creativecommons.org/licenses/by/ $4.0 /)$.

Keywords: landscape permeability; landscape fragmentation; matrix resistance; habitat suitability modelling; maxent models; circuitscape

\section{Introduction}

The increase in anthropogenic pressures has greatly affected species movement worldwide [1]. The dispersal of individuals among populations is essential to counterbalance the negative effects of habitat isolation and to maintain population and community persistence and dynamics [2,3]. Ecological corridors that ensure dispersal can be defined as linear strips that provide a near continuous pathway promoting functional connectivity between core areas of biodiversity [4-6]. Key conceptual frameworks and accessible tools based on graph and circuit theory have been proposed to help locate ecological corridors through landscape connectivity analysis [7-9]. However, these frameworks are based on different, and often untested, assumptions (e.g., dispersal or matrix resistance) that can lead to inconsistent spatial prioritization [10-12]. To overcome this issue, empirical procedures are needed to validate different landscape connectivity approaches that pinpoint ecological corridors.

Connectivity conservation planning aims to maintain or restore ecological corridors for multiple target species. Combining the results of landscape connectivity approaches for a wide range of species creates theoretical problems, such as how to generalize a patch-corridor-matrix model for species with different ecological requirements [13]. These limitations were overcome in different ways, using more or less realistic hypotheses or proxies that can distort the results [14-17]. A first option is to use land cover and expert opinion as a proxy for species presence and landscape resistance to movement to inform researchers on potential multiple-species movements in the matrix [18]. A second option is to produce a habitat suitability map for each species by relating species-presence data 
with environmental predictors, transforming the habitat suitability map into matrix resistance, and, finally, combining the maps for several species [19]. A third option relies on the concept of umbrella species, which "confer a protective umbrella to numerous co-occurring species" [20]. Following Calabrese \& Fagan [21], one can expect that the realism of landscape connectivity approaches, and thus the accuracy of ecological corridor locations, is related to data calibration, considering that multispecies data provide more information than data from one umbrella species, and even more so than a habitat proxy derived from land cover data [22]. A validation procedure that is capable of determining the most relevant landscape connectivity approach, according to this simple paradigm that links realism and calibration data, can prove its usefulness to evaluate ecological corridor locations.

Very few of the studies that have explicitly sought to map ecological corridors actually attempted to validate their approaches (less than 25\%, [23]). Inference makes it possible to compare network-based metrics according to coefficient of determination or likelihood-based indices. However, these indices are not directly related to ecological corridor locations. The corridor locations predicted by different connectivity models can be validated with telemetry data or reference genetic distances [24-28]. However, in a review of the use of biological data in combination with landscape graphs, Foltête et al. [29] found that telemetry and molecular data represent only $8.4 \%$ of the studies and are much less used than presence data, which can be easily extracted from existing databases. Therefore, further validation procedures are required, especially those using presence data not collected from telemetry. Foltête et al. [29] also noted that few papers used biological data (regardless of data type), following the classical statistical procedure of validation that consists in calibrating a model with a subsample of data and validating it with another subsample [30]. Taking advantage of the classical data partitioning procedure used in statistics to calibrate and validate landscape connectivity approaches with independent species presence data could fill the absence of a validation procedure for ecological corridors.

Ecological corridors are mostly modelled from graph and circuit theory that make different assumptions about species movement. These methods can be disconnected from managers and stakeholder requirements that need to target priority areas and define conservation and restoration areas based on operational costs. On the one hand, circuit theory used resistance surfaces to produce current maps that aim at encompassing all possible dispersal paths between source habitats based on the assumption that species randomly move across the landscape [22]. However, the number of important paths can be too high to satisfy the needs of managers and stakeholders to target priority areas. On the other hand, single a least-cost path is defined from resistance surfaces and assuming that this path support most of the movements between habitat patches [31]. Beyond these two cases, managers and stakeholders need to define the number of ecological corridors to protect, according to both biological hypothesis realism and their ability to support landscape conservation and restoration. A new validation procedure, independent of the modelling framework, is needed to compare and evaluate landscape connectivity assumptions and ecological corridor location.

In this study, we propose a new validation procedure based on independent speciespresence data to evaluate the accuracy of the locations of ecological corridors predicted by landscape connectivity models. Our validation method is based on the hypothesis that the concerned species are more likely to be found along or near their predicted corridors, provided these corridors were properly modelled. The validation procedure is independent from the modelling framework, because it evaluates the final output of landscape connectivity approaches (i.e., ecological corridor locations). Therefore, the procedure can be applied to any type of models (e.g., based on expert opinions, least-cost paths or circuit theory) that map ecological corridors. This issue is especially important because routine procedures validate intermediate model outputs, and, often, resistance values or habitat suitability; however, they do not provide information about the validity of the entire modeling process [23]. We illustrated the use of this procedure for four forest 
birds in an agricultural valley located in the French Alps. For this study case, we applied circuit theory to model all of the possible dispersal paths, and considered several thresholds of current values to account for different possible levels of resources dedicated to ecological corridor conservation and restoration by managers and stakeholders. The aim of the study case was to compare three modelling approaches to design multispecies corridors: (i) a habitat approach that relies upon a land cover map used as a proxy for species presence, (ii) an umbrella-species approach based on presence-only data of Sitta europaea, an umbrella species for woodpeckers, and (iii) a multispecies approach based on presenceonly data of Sitta europaea and three woodpecker species: Dendrocopos major, Dryocopus martius and Dendrocopos minor. Our validation procedure is expected to demonstrate that ecological corridors were better localized with the multispecies-and then the umbrella species-approaches that are based on the use of species data, and lower for the habitatbased approaches that rely on land cover and expert opinion. Compared to the multispecies approach, other approaches have the advantage of reducing the cost associated with data collection. Our validation procedure was also expected to give new insights about the degree of decrease in accuracy (compared to the multispecies approach) and the relevance of the umbrella and habitat approaches.

\section{Materials and Methods}

\subsection{Validation of Ecological Corridor Locations Based on Corridor Score}

We proposed the following validation index based on the hypothesis that the corridors, or their nearby environment, concentrate species presence (or validation) points:

$$
\text { Corridor score }=\frac{1}{N} \sum_{i=1}^{N}\left(\frac{\text { Drandom }_{i}-\text { Dobserved }}{\text { Drandom }_{i}}\right)
$$

where $N$ is the number of random draws $i$, Drandom $_{i}$ is the average cost distance (or Euclidean distance) to the corridors from randomly selected points in the landscape for draw $i$, and Dobserved is the average cost distance (or Euclidean distance) to the corridors from the validation points. The corridor score index is obtained by averaging $N$ random draws from a number of random points equal to the number of validation points. An index close to 1 means the validation points are close to the corridor in terms of resistance distance, which validates the hypothesis that the corridor, or its nearby environment, concentrates the potential dispersal flows. An index close to 0 means the approach is no better than a null model and invalidates the above hypothesis. A negative index means that the matrix, not the corridor, concentrates the potential dispersal flows. The difference between Drandom $_{i}$ and Dobserved is sensitive to the distribution of resistance values, which could be problematic to compare different resistance surfaces. For example, if the distribution of matrix resistance values of a first resistance surface is more flat-tailed compared to a second one, then the distance between two random pixels has a greater chance of being larger, which can mistakenly lead to the conclusion that the first method is less accurate. To deal with this issue, we divided the difference between Drandom $_{i}$ and Dobserved by Drandom $_{i}$. As a consequence, the corridor score is robust enough to compare different matrix resistance classifications and select the most accurate.

\subsection{Study Case to Illustrate the Validation Procedure}

We illustrated the use of our new validation procedure to compare several landscape connectivity approaches to pinpoint ecological corridors in a study area $\left(755 \mathrm{~km}^{2}\right.$, latitude: 45.223826, longitude: 5.453339) located in the northern French Alps (Figure 1). Two forested mountain ranges are located along the western and the eastern edges of the study area. They are separated from each other by a rural matrix $\left(631 \mathrm{~km}^{2}\right)$, which concentrates several potential dispersal barriers for forest species: urban areas linked with transport infrastructure, a concentration of intensive walnut orchards and agricultural fields. The 
presence of small woodlands and hedgerows may facilitate forest species movement (Appendix A for a complete description of the study area).

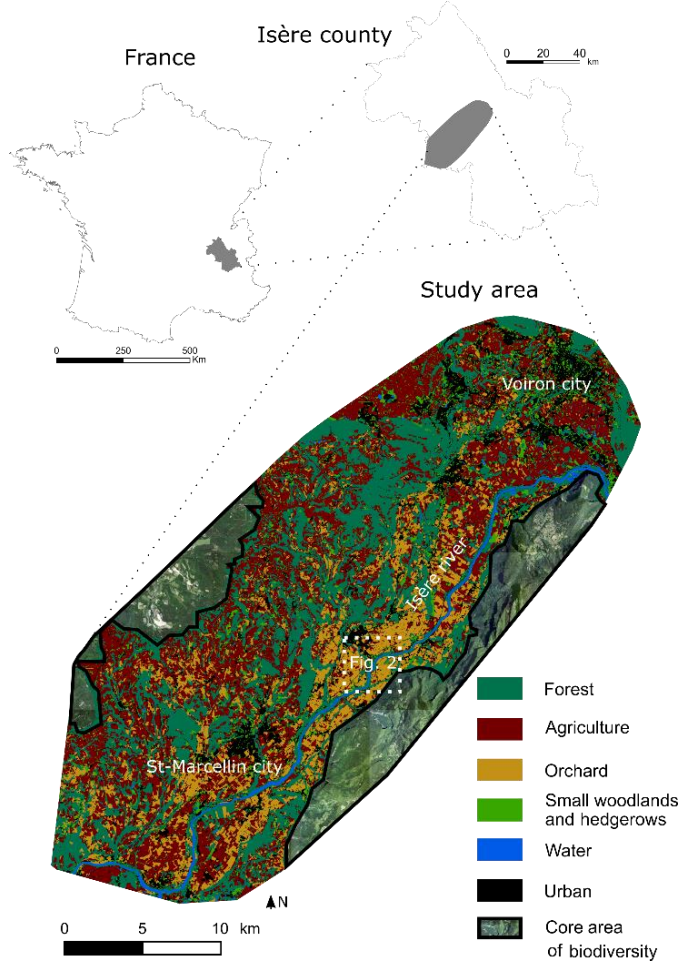

Figure 1. Study area with the land cover in the matrix and the core areas of biodiversity (determined by ortho-imagery). For clarity, intermediate habitat patches are not depicted, because they depend on species.

We selected four forest model species in accordance with the size of the study area and species dispersal distance (Appendix B). We extracted opportunistic presence data for the period 2014 to 2019 from the French Bird Protection League's database. After correction for sampling bias (Appendix B), 396, 665, 43 and 31 presence records were retained for Sitta europaea, Dendrocopos major, Dryocopus martius and Dendrocopos minor, respectively. S. europaea is a secondary cavity nester and an umbrella species for woodpeckers [32]. Ecological corridors were modelled following three classical approaches to define matrix resistance.

Approach 1, hereafter called "habitat", was based on expert opinion and the literature. Following previous parameterizations applied to forest mammals, resistance values were fixed to 1 for forest, 10 for small woodlands and hedgerows, 300 for orchards, 700 for agriculture, 900 for water and 1000 for urban areas [10,33]. These resistance values were considered valid for forest birds.

Approach 2, hereafter called "umbrella species", consisted in modelling matrix resistance from presence-only data of Sitta europaea and Maxent software (American Museum of Natural History, New York, NY, USA) that can provide an accurate habitat suitability index, even with a small sample size [34,35]. We calibrated the Maxent model using 50\% of the presence data related to landscape metrics derived from the proportion of each land cover in $100 \mathrm{~m}$ buffer (also including a Shannon land cover diversity index; Appendix C). The habitat suitability index was evaluated using the AUC (area under the curve) index provided by Maxent software [30]. The habitat suitability index was transformed into matrix resistance using a negative exponential function, following Keeley et al. [11] and Duflot et al. [36].

Approach 3, hereafter called "multispecies", consisted first in modelling matrix resistance separately for the three woodpecker species Dendrocopos major, Dryocopus martius, 
Dendrocopos minor, and Sitta europaea, following the method presented in approach 2, then combining the four single-species connectivity maps to obtain a multispecies corridor map (by adding current values, see next paragraph). Single-species connectivity maps were standardized to give equal weight to each of the four species.

We used the Circuitscape software (National Center for Ecological Analysis and Synthesis, Santa Barbara, CA, USA) with the three previous resistance surfaces to map the cumulative current and pinpoint where the potential flows of individuals are concentrated accounting for all possible paths [7] (Appendix D). We considered a directional cumulative flow of current across the whole study area, from one range to the other [37]. Intermediate habitat patches were defined according to the species minimum area requirement and land cover (Approach 1) or suitability threshold (Approaches 2 and 3; Appendix D). We used a threshold approach to define ecological corridors: the cumulative current flow was vectorised with several thresholds (at the 55th, 65th and 75th quantiles) to delineate the corridors and to account for various levels of resources dedicated to ecological corridor conservation and restoration by managers and stakeholders [28]. Only the polygons that continuously linked (i.e., with no breaches) the core areas were considered as corridors. Next, we calculated the proportion of overlaid corridors among approaches (as a measure of consistency) and the corridor score (as a validation index) using fifty percent of the presence data. The validation index was calculated for each approach and threshold of cumulative current. The four species were used to compute the validation index for each of the landscape connectivity approaches. We tested the sensitivity of the corridor score to these three parameters with ANOVA, for simple effects and all dual interactions. All statistical analyses were performed with R software v.3.6.0. A flowchart of the modelling framework is provided in Figure 2.

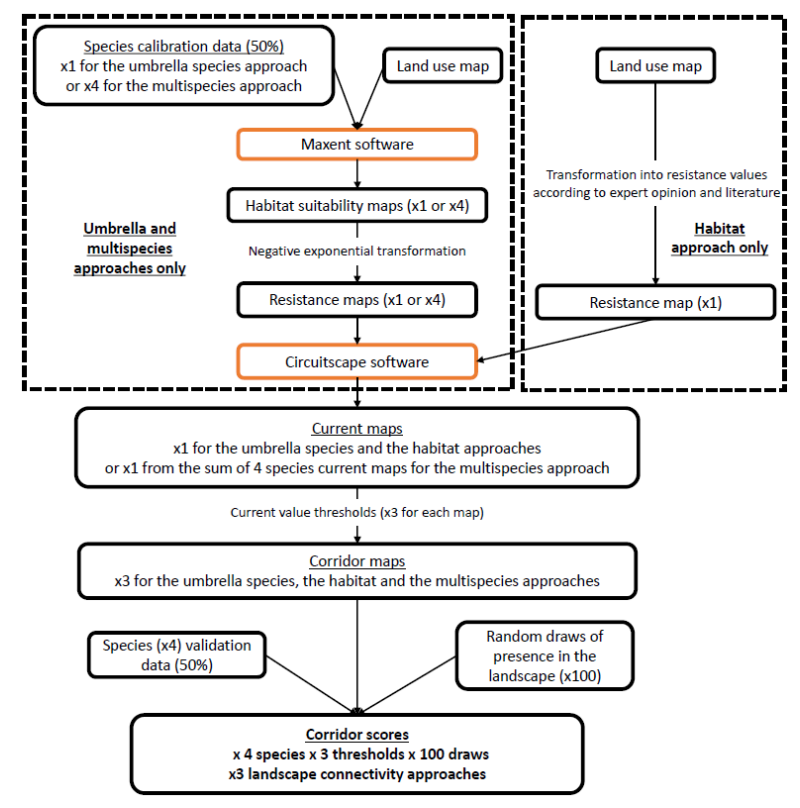

Figure 2. Representation of the modelling framework that compare three landscape connectivity approaches from a new validation index (corridor score). Maxent software provides an internal validation procedure (based on data partitioning) that only validates habitat suitability maps but not the next modelling steps. Other validation procedures validate resistance surfaces and suffer from the same limitations [23]. The corridor score validates the final output of the landscape connectivity approaches (ecological corridor maps) and thus the overall modelling framework. As a consequence, our validation procedure detailed in the first section of the Materials and Methods is totally independent from the modelling framework (i.e., from the use of Maxent software to the threshold of current maps) that was defined here for the application to a landscape study case. The corridor score can be computed to compare any other modelling frameworks that aim to map ecological corridors. 


\section{Results}

Habitat suitability models were quite valid with AUC indexes ranging between 0.70 and 0.72 , except for D. martius, for which model validity was rather low (AUC $=0.63$ ). A detailed description of the results provided by Maxent modelling is provided in Appendix C. Ecological corridor tracks clearly differed comparing the three approaches (Figures 3 and 4). We selected a sub-area, within our study area, to illustrate the consistencies and differences between two highly contrasted models (the multispecies and habitat approaches) and the consequences of these differences on the ecological corridor locations the models predicted (Figure 3). A corridor linking two other corridors to the south-west appeared with the habitat approach, but not with the multispecies approach (Figure 3).

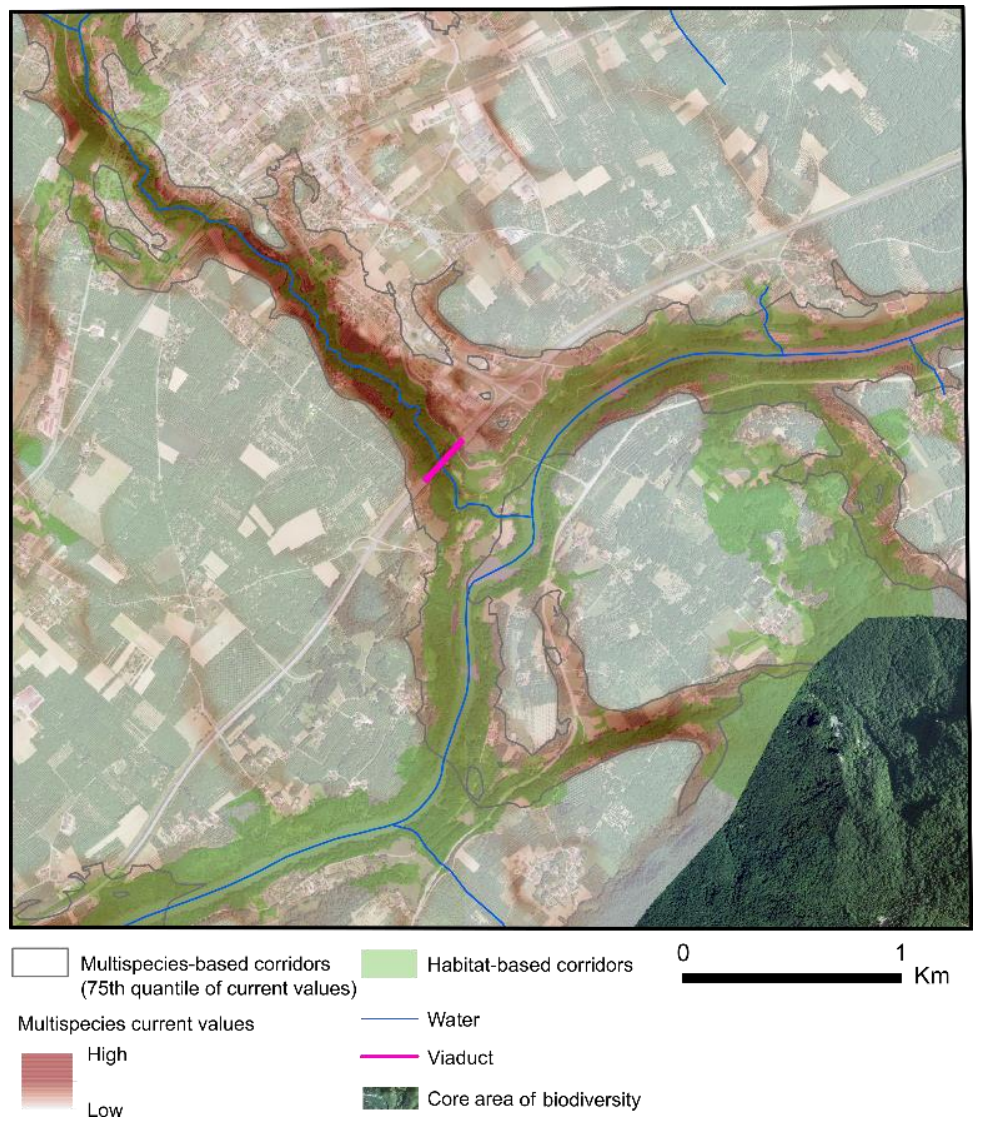

Figure 3. Example of important ecological corridors related to the presence of riparian forests in a selected sub-area of the study landscape. This map shows the inconsistencies between the two most contrasted approaches (multispecies and habitat approaches) to illustrate the need of a validation procedure that measures the accuracy of ecological corridor locations. For example, a corridor linking two other corridors to the south-west appeared with the habitat approach but not with the multispecies approach. Background map is an ortho-image.

At the scale of the study area, the multispecies and umbrella-species approaches showed more similar locations for the highest current values; however, the habitat approach differed more significantly (Figure 4). From the highest (75th) to the lowest (55th) quantile, the proportion of corridors shared between the multispecies and the umbrella-species approaches ranged from 0.74 to 0.83 , between the multispecies and the habitat approaches from 0.44 to 0.84 , and between the umbrella-species and the habitat approaches from 0.44 to 0.60 (Appendix $\mathrm{E}$ for a full comparison). Consequently, corridor score depended on approach $(\mathrm{F}=387.5, p<0.0001)$, but also species $(\mathrm{F}=887.3, p<0.0001)$, threshold quantile $(\mathrm{F}=364.0, p<0.0001)$ and the interactions between species and approach $(\mathrm{F}=76.1$, $p<0.0001)$ and between species and threshold quantile $(\mathrm{F}=93.3, p<0.0001$; Appendix $\mathrm{F})$. 


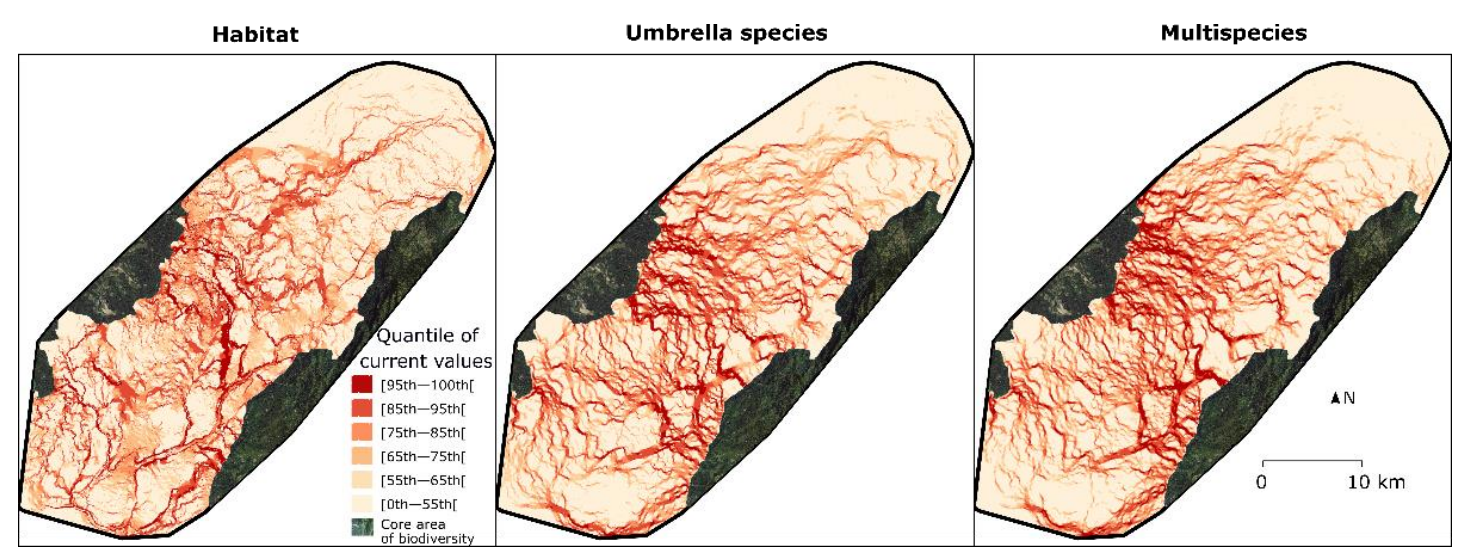

Figure 4. Comparison of the current maps for the three approaches used to define ecological corridors. These maps accounted for all the possible dispersal paths making difficult to prioritize key corridors. For each method, three quantiles of current values (55th, 65th and 75th) were used to delineate ecological corridors in order to account for a different possible level of resources dedicated to ecological corridor conservation and restoration by managers and stakeholders. Core areas of biodiversity (the Chambarans and Vercors ranges) were defined according to the local application of the green veining policy. They were used to generate directional flows of current across the whole study area. Intermediate habitat patches are not depicted for clarity purpose (especially for the multispecies approach).

The multispecies approach obtained the highest corridor score $(0.69 \pm 0.12)$, followed by the umbrella-species approach $(0.55 \pm 0.25)$, then the habitat approach $(0.38 \pm 0.37)$ with the lowest score (Figure 5). Additional results showed that the corridor score was robust to the distribution of the resistance value range (Appendix $G$ ).

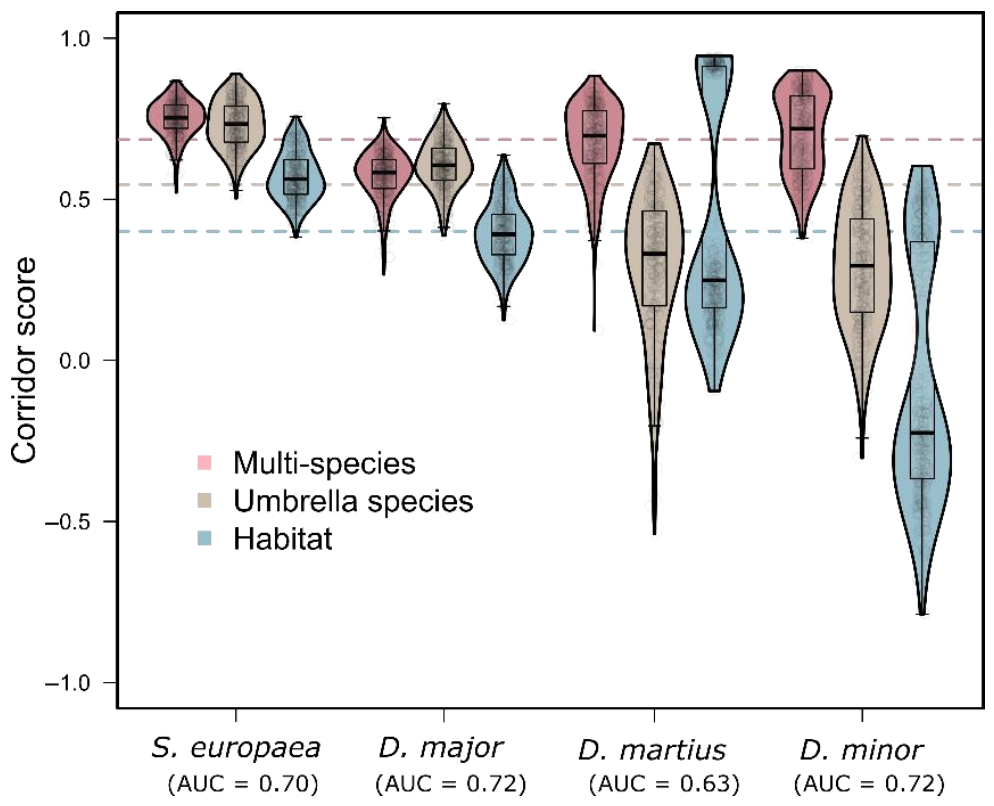

Figure 5. Variations in corridor score according to landscape-connectivity approach and species used for validation in an illustrative study area. Corridor scores evaluate the accuracy of predicted ecological corridor locations thanks to independent presence species validation data (see Section 2.1). The graph shows a combination of boxplots and violin plots representing quantile and kernel density for 100 comparisons of random draws (light grey points) with species validation points for three thresholds of current values used to delineate the corridors. Dotted lines indicate median values according to the approach. The area under the curve (AUC) is another validation index related to the quality of habitat suitability models. This index is species-specific and does not allow for the comparison of different approaches and the validation of ecological corridor locations. It is depicted for comparison purpose with the corridor score. 
Regardless of the approach, the corridor score decreased from S. europaea $(0.70 \pm 0.11)$ to D. major ( $0.55 \pm 0.13)$, D. martius $(0.47 \pm 0.30)$ and D. minor $(0.39 \pm 0.42)$. For S. europaea, the corridor scores were similar for the umbrella-species approach and the multispecies approach (Figure 5). The median corridor score was the lowest for D. minor $(0.39 \pm 0.42)$, and especially low with the habitat approach $(-0.23 \pm 0.38)$. The results also showed that the multispecies and the umbrella species approaches performed equally well for S. europaea and D. minor (Figure 5).

\section{Discussion}

\subsection{Validation of Ecological Corridor Locations Based on Corridor Score}

We propose a new procedure to validate ecological corridor locations, based on independent presence-only data, under the hypothesis that species should occur within or near the corridors. Our procedure is applicable regardless of how the corridors are defined (e.g., least-cost paths, circuit theory, expert-based) because we did not base our validation index on a specific measure, such as current values only related to circuit theory, for example. The corridor score can then be computed using Euclidean or resistance distances. It is robust to the distribution of the resistance value range, meaning that (i) it can be used to select the best way to classify resistance values or to transform habitat suitability into resistance and (ii) it can be applied to other species with different habitat suitability requirements Here, we illustrated the validation procedure putting forward its ability to compare different landscape connectivity approaches used to map multispecies corridors and to select the most accurate approach. Our validation procedure has important (i) theoretical implications the comparison and validation of model assumptions and (ii) practical implications for managers and stakeholders who wish to select the best connectivity approach and validate ecological corridor locations, defined according to the level of resources dedicated to corridor conservation and restoration.

\subsection{Validation of Ecological Corridor Locations Using an Illustrative Landscape}

We illustrated that ecological corridor maps could be quite different depending on the approach. These maps are often directly use in landscape planning, as a consequence a validation procedure which selects the most accurate map is critical to prioritize areas to protect [38]. We found that the number of ecological corridors (quantile threshold) selected for conservation and restoration action is correlated to the corridor score. This result shows the importance of validating ecological corridor tracks, especially when using an operational definition of corridors, related to the area that managers and stakeholders are able to protect or restore. There were no interactions between the threshold quantile used to select the number of ecological corridors and the landscape connectivity approach. Therefore, it is possible to select the method that gives the best corridor score independently of the choice of the amount of ecological corridors. This result also implies that our procedure can be used to compare different approaches, in a given landscape, independently of the number of ecological corridors and intermediate habitat patches of this landscape. Despite some differences, the ecological corridors were much more concordant between the multispecies and the umbrella species approaches than between these two approaches and the habitat approach. This may be explained by the similarity between the first two methods, which both integrate species data related to landscape metrics. We showed that our validation procedure ranked landscape connectivity approaches as expected, i.e., that multispecies presence data provide more accuracy to locate ecological corridors than the use of umbrella species or habitat proxies [12,21]. Indeed, the corridor score was higher for the multispecies approach and lower for the habitat approach. The ability of the multispecies approach to accurately locate ecological corridors for several species is in accordance with previous findings $[39,40]$. The gap of corridor score between the multispecies and the habitat approaches was expected, given the study of Meurant et al. [12], which showed that multispecies presence data reflect the reality better than a habitat proxy. This difference is also partly due to how the landscape is modelled: either locally for the habitat 
approach, or accounting for the surrounding landscape context for the multispecies and the umbrella-species approaches. Indeed, the importance of landscape factors has been highlighted for woodpeckers [41,42]. The accuracy of the umbrella species approach is debated because the results depend on the choice of the umbrella species and possibly on the landscape context [12,21,22,43]. Meurant et al. [12] also compared different selections of surrogate species for spatial prioritization with reference to the full set of species. In contrast with our hypothesis, they concluded that umbrella species are poor indicators of many species' requirements and that an indirect approach based on habitat is preferable, even if important areas, for landscape connectivity conservation, may not be identified. In our case, the accuracy of the umbrella-species approaches was expected, due to an appropriate choice of the umbrella species, since Sitta europaea is considered a good surrogate for related woodpeckers [32]. In contrast, the umbrella species selected by Meurant et al. [12] is only a moderately effective surrogate, though for a wider range of contrasted species (14 species).

\subsection{Differences in Corridor Score among Species}

We also tested corridor score sensitivity and performance against species and the current threshold we used to delineate corridors. The corridor score was the highest for Sitta europaea. This was expected, because the presence data of this species were used for calibration in two of the three models (umbrella and multispecies models), while presence data of the woodpecker species are only used in the multispecies approach. The median corridor score was the lowest for $D$. minor. The median corridor score for the habitat approach was negative for this species, indicating that the ecological corridor locations were less accurate than in a null model, and that our hypotheses on matrix resistance were globally inconsistent. This result was easily explained, because the proportion of water in the local environment (and the Shannon land use diversity index) was the main driver of environmental suitability, and not the proportion of forest (Appendix C). This illustrates the ability of our validation procedure to detect a misclassification of matrix resistance values, even with only a few validation points. Interestingly, the multispecies approach performed similarly to the umbrella species approach for Sitta europaea, indicating that including data from other species did not decrease the accuracy of the multispecies approach for this species. Both methods worked equally well for Sitta europaea and Dendrocopos major. For D. martius, the habitat approach had a high corridor score only when the discrimination of ecological corridors from the matrix was not very selective (i.e., when the 55th quantile of current values was used to delineate the corridors). Finally, between-species differences in corridor score were consistent and, as expected, our validation procedure was able to indicate that implementing a multispecies approach should guarantee maximal prediction accuracy in most cases.

\subsection{Comparison with Other Validation Procedures}

The AUC values indicated that the validity of the habitat suitability models was quite satisfactory among three of four species. However, this index does not inform us about spatial arrangement of suitability, and even so on ecological corridors. For example, an important corridor can integrate poorly suitable landscape elements over short distances, especially when these elements connect more suitable areas linking habitats. The AUC index does not allow to compare different approaches (e.g., to define matrix resistance) because it evaluates only the quality of the habitat suitability model. The following steps, such as matrix resistance or ecological corridors modelling, cannot be evaluated in the light of this index. As a consequence, landscape connectivity studies that validate modelling performance using an AUC or a receiving operator curve obviously miss the evaluation of connectivity maps [36]. This is the reason why it is important to use complementary indexes that validate one final output of a given landscape connectivity approach (i.e., ecological corridor locations) and not only an intermediate output (such as habitat suitability or resistance values [23]). In contrast, we showed that the corridor score gives a detailed 
insight about ecological corridor locations according to approaches used to define resistance and the threshold quantiles that delineate ecological corridors.

Some studies used inference to select the best connectivity metrics according to the quality of the fit defined from a coefficient of determination or likelihood-based indices [44]. These indices are only indirectly related to the spatial configuration of the ecological network, which makes them less useful for practitioners concerned with ecological network design. Osipova et al. [45] used a combination of models to assess the links between connectivity metrics and abundance, density and total number of elephants with aerial and field surveys. Their significant investigatory effort provides a body of evidence supporting the fact that corridor delineation derived from a landscape-connectivity approach has strong predictive power and is useful in spatial conservation prioritization [45].

Other studies used the standardized difference and the z-scores of accumulated costs, at observed and random radio-tracking fixes, to validate ecological corridor location, though the cost of telemetry technology greatly limits its general application $[26,28,46]$. Independent data collected during specific sampling campaigns (capture-release-recapture, camera sampling, sand traps or vehicle collision data) can also be highly relevant to validate landscape connectivity approaches, but only for the species that can be detected in such a way $[24,47,48]$ (however, see [49]). However, the cost of collecting such data can be prohibitive and this partly explains why most of connectivity studies are not validated [23]. Our validation procedure using the classical data partitioning into calibration and validation folds thus fills this gap.

\subsection{Limits}

Our study did not overcome the limitations recently debated concerning the link between presence data, dispersal movement and the effective reproduction of migrants [50,51]. Presence data relate both to habitat suitability and species movements, and both processes are confounded when movements decrease due to mortality risk or avoidance of less suitable types of land cover. Fletcher et al. [51] question the consequences of neglecting to distinguish between these two processes, though they do recognize that the focus on matrix resistance has led to major advances in the understanding of connectivity. They propose a new connectivity model that separates mortality and movement behaviour. We acknowledge that presence data are indirectly related to movement and do not make it possible to discriminate between foraging, dispersal and migration, or to quantify the successful reproduction of migrants, with its consequences on genetic population diversity [52].

\section{Conclusions}

In this study, it was expected that the multispecies approach, based on the use of more calibration data, would be more accurate. The advantage of using other approaches is to reduce the cost associated with data collection. However, it is necessary to evaluate to what degree this implies a loss of accuracy in the location of ecological corridors. The application of our procedure to a case study allows us to conclude that the difference in accuracy between the multi-species approach and the umbrella species approach can be negligible, but only for species very close to the selected umbrella species. We also conclude that the use of habitat as a proxy for species presence provide poor results. Despite the cost associated with data collection, only the multispecies approach precisely maps ecological corridors for all the species.

Our validation procedure has several theoretical and practical advantages: (i) it provides a validation procedure based on easily accessible data; (ii) it can be used to select the most realistic landscape connectivity approach; (iii) it can detect a misclassification of matrix resistance values from only a few validation points and can help select the best function to transform habitat suitability into resistance values; (iv) it is independent from the modelling framework; and (v) it is easy to calculate after using software designed for connectivity conservation planning [7-9]. Finally, to take a step back from our validation procedure, we need to evaluate how the corridor score ranks different landscape connectiv- 
ity approaches compared to more robust validation indices based on telemetry or genetic distances in contrasted study landscapes [25].

Author Contributions: Conceptualization, E.L. and L.B.; methodology, E.L. and L.B.; validation, E.L. and L.B.; formal analysis, E.L.; investigation, E.L. and L.B.; resources, E.L. and L.B.; data curation, E.L.; writing_original draft preparation, E.L.; writing—review and editing, E.L. and L.B.; visualization, E.L.; supervision, L.B.; project administration, L.B.; funding acquisition, L.B. All authors have read and agreed to the published version of the manuscript.

Funding: This research was funded by the FEDER project "Trame verte forestière", grant number RA0017232.

Institutional Review Board Statement: Not applicable.

Informed Consent Statement: Not applicable.

Data Availability Statement: The data presented in this study are available on request from the corresponding author. The data are not publicly available because they were used under license for this study and cannot be used without the French Bird Protection League agreement (Ligue de Protection des Oiseaux, LPO).

Acknowledgments: We are grateful to the French Bird Protection League, and especially to Rémi Fonters for providing us with species data.

Conflicts of Interest: The authors declare no conflict of interest. The funders had no role in the design of the study; in the collection, analyses, or interpretation of data; in the writing of the manuscript, or in the decision to publish the results.

\section{Appendix A. Detailed Study Area Description}

Land cover (Figure 1) is mainly composed of forests (patch area $>0.5 \mathrm{ha}, 32 \%$ ) and agriculture $(33 \%)$, followed by orchards $(14 \%)$, urban areas $(11 \%)$, small woodlands (patch area $\leq 0.5 \mathrm{ha}$ ) and hedgerows $(7 \%)$ and water (streams and water bodies, $2 \%$ ). The land cover map was created from the BD TOPO®data base (2018) of the French National Institute of Geographic and Forest Information (IGN) with thematic vector layers for vegetation, built-up areas (urban areas, roads, railway lines) and hydrography (streams and water bodies). The French Graphic Parcel Register (2017) was used to map agricultural lands. These layers were rasterised to $5 \mathrm{~m}$ before overlay. The resulting land cover map contained $18 \%$ of missing data, mainly urban areas. To fill these gaps, an interpolation was carried out with the ArcMap v.10.5.1 software and the ArcGIS tool "Euclidean distance". Next, streams and water bodies, then roads and railways, were overlaid on the land-cover map. We aimed to locate ecological corridors through the matrix in an alpine valley between two core areas of biodiversity (the Chambarans and Vercors massifs) defined according to the local application of the green veining policy.

\section{Appendix B. Sampling Bias Correction According to Species Traits}

We extracted presence data for the period 2014 to 2019 from the French Bird Protection League's database: 653 presence records for Sitta europaea, and 1156, 46 and 41 for Dendrocopos major, Dryocopus martius and Dendrocopos minor, respectively. We used this presence data to define the boundaries of the study area from a convex hull (extended by a buffer of $100 \mathrm{~m}$ ) in order to exclude unprospected areas and avoid extrapolation. To correct for sampling bias, we followed Kramer-Schadt et al.'s [53] spatial filtering method to remove nearby presence points according to a threshold distance (if too close, presence points could be redundant). This distance was defined as $100 \mathrm{~m}$ based on species home-range and spatial filtering retained 396, 665, 43 and 31 points for Sitta europaea, Dendrocopos major, Dryocopus martius and Dendrocopos minor, respectively.

More precisely, we extracted median dispersal distances from Lislevand et al. [54]. They were $1.23 \mathrm{~km}, 2.87 \mathrm{~km}, 5.54 \mathrm{~km}$ and $1.18 \mathrm{~km}$ for Sitta europaea, Dendrocopos major, Dryocopus martius and Dendrocopos minor, respectively. Then, allometric relationships provided 
by Sutherland et al. [55] and Bowman et al. [56] were used to predict the corresponding home-range size (1.1 ha, $5.7 \mathrm{ha}, 21.3 \mathrm{ha}$ and $1.0 \mathrm{ha}$, respectively) and maximal dispersal distances $(12.0 \mathrm{~km}, 28.0 \mathrm{~km}, 54.1 \mathrm{~km}$ and $11.5 \mathrm{~km}$, respectively) for the four species. Finally, we set the threshold distance at $100 \mathrm{~m}$, a value close to the minimal radius of the home-range size of the four species.

\section{Appendix C. Habitat Suitability Modelling Using Maxent}

We calibrated the habitat suitability model using $50 \%$ of the presence data through the Maxent software. The landscape metrics were derived from the land cover map and calculated with the Chloe-4.0 software [57]. We calculated the proportion of each land cover class using sliding windows (buffer radius of $100 \mathrm{~m}, 5 \mathrm{~m}$ between two adjacent windows). The windows were also used to calculate a landscape heterogeneity index: the Shannon diversity index or SHDI [57]. Buffer sizes were defined to prevent the windows around the points from overlapping. Checking for correlations among the landscape metrics indicated that they were not excessively correlated (Pearson's correlation coefficient $<0.70$ ). The importance of the individual landscape metrics and uncertainties were assessed with a Jackknife test based on three random selections of background points (or pseudo-absence [53]).

Variable importance ranking showed that the two most important landscape metrics, for the four species, include proportion of forest or water, or the Shannon diversity index (Figure A1). The Shannon diversity index always had either a null or positive effect on species presence, indicating that the species required multiple land covers such as forest and water. Proportion of forest and water were positively correlated with species presence, except when forest and water proportions were very high (with a few exceptions depending on species, Figure A1). The effect of the proportion of small woodlands and hedgerows was not consistent among species, while the effect of the proportion of orchards and urban areas was generally negative. The response of Dendrocopos minor differed from the other three species: for this species, the effect of forest proportion did not show a clear trend and the proportion of small woodlands and hedgerows had a negative effect.

Our results showed that species presence could benefit from a diversity of land covers including forest, water and small woodlands and hedgerows. This complementation effect indicates that these land cover have a positive effect as long as they are not too dominant in the local environment [58]. This result relates to the importance of riparian forests, which allow species to move along streams. The role of riparian forests as ecological corridors as well as their use by woodpeckers have been highlighted [59-61]. Cultivated fields, orchards and urban areas had a consistently negative impact on species presence, except for Dendrocopos minor: this bird mainly responded positively to the Shannon diversity index and to the proportion of water, and negatively to the proportion of small woodlands and hedgerows, in concordance with its ecology $[62,63]$. D. minor's differing response was expected given that the species is more generalist than the other three and is not rare in open habitats [63]. 


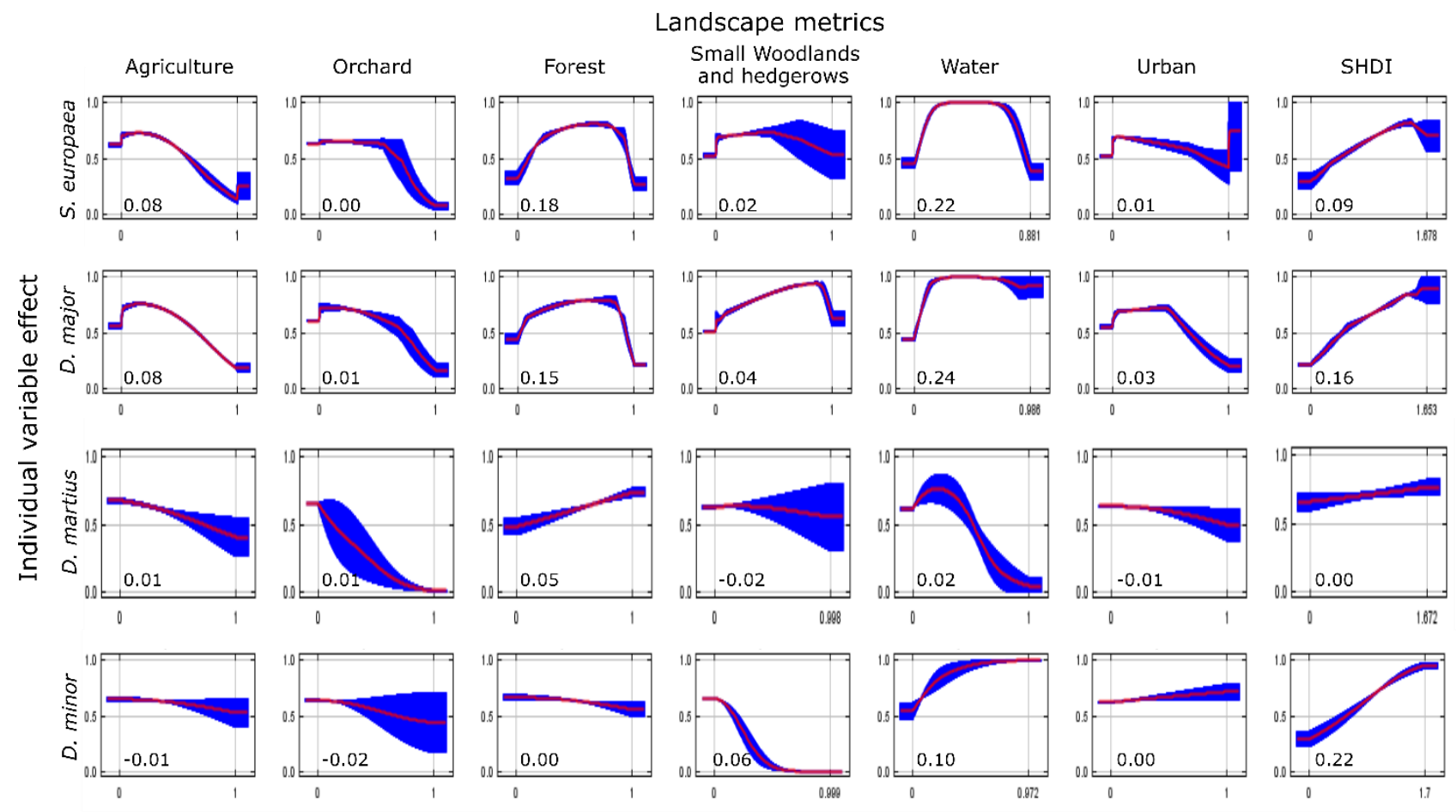

Figure A1. Dependence of predicted habitat suitability on landscape metrics according to Maxent models. Landscapes metrics were calculated within a circular radius of $100 \mathrm{~m}$. The individual importance of each landscape metric was calculated with a Jackknife test based on 3 random selections of background points. SHDI: Shannon diversity index.

\section{Appendix D. Landscape Connectivity Model}

Following [11-36], the habitat suitability index (HSI) obtained from Maxent models were transformed into resistance values (ranging from 1 to 1000) following a negative exponential transformation function to strengthen the barrier effect of the least favourable areas.

If HSI $\geq$ threshold (in species habitat): resistance was assigned to 1.

If HSI < threshold (in matrix): we used Equation (A1) to assign resistance.

$$
\text { Resistance }=e^{\frac{\ln (0.001)}{\text { threshold }} \times \mathrm{HSI}} \times 10^{3}
$$

Resistance is inversely proportional to the permeability of the matrix. The function (Equation (A1)) assigned a resistance value of 1000 when HSI equalled 0 and of 1 when HSI was greater than or equal to the HSI threshold defined by Liu et al. [64].

\section{Appendix E. Comparison of Ecological Corridor Locations among Approaches Used to Define Matrix Resistance}

We compared the proportion of overlaid corridors among three approaches used to define matrix resistance. The multispecies and umbrella-species approaches showed globally similar locations for the highest current values but the habitat approach differed. From the highest (75th) to the lowest (55th) quantile, the proportion of corridors shared between the multispecies and the umbrella-species approaches ranged from 0.74 to 0.83 , between the multispecies and the habitat approaches from 0.44 to 0.84 , and between the umbrella-species and the habitat approaches from 0.44 to 0.60 (Figure A2).

In view of these results, we do not necessarily advocate the use or more data, or data that are better related to movement and its consequences on genetic diversity (Calabrese and Fagan 2004). Instead, connectivity-approach accuracy should be defined according to specific objectives. For example, in our study, all three methods made clear the central role of riparian forests. In this case, the habitat approach would likely be the best approach 
because it can signal the importance of riparian forests at a lower cost, despite its many errors in locating ecological corridors. On the other hand, the multispecies approach would be the best way to accurately delineate ecological corridors in order to integrate accurate corridor layouts into landscape connectivity planning.

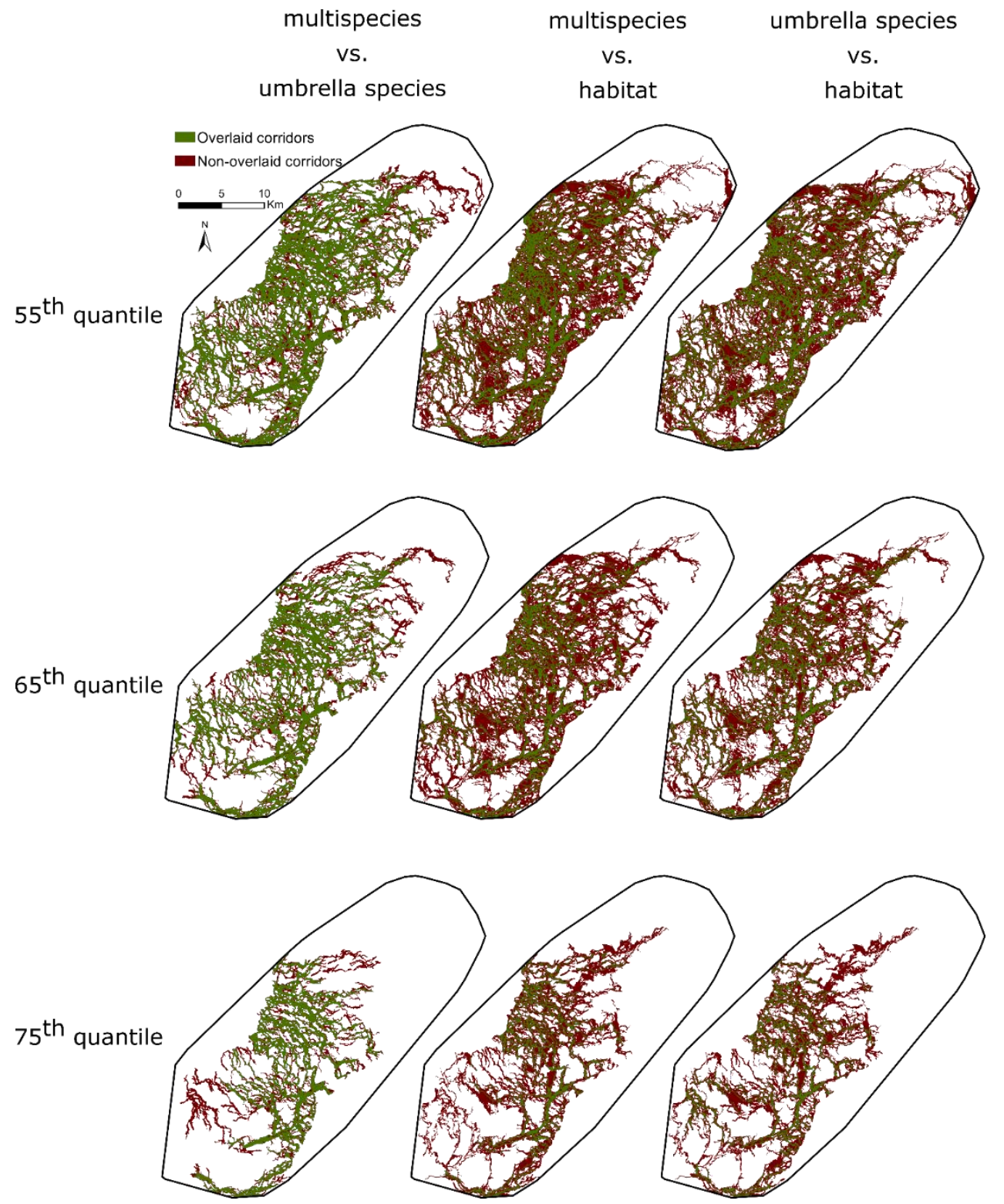

Figure A2. Ecological-corridor overlay between pairs of approaches for the three quantiles used to delineate corridors from current values (55th, 65th and 75th). 
Appendix F. Comparison of Ecological Corridor Locations among Approaches and Species

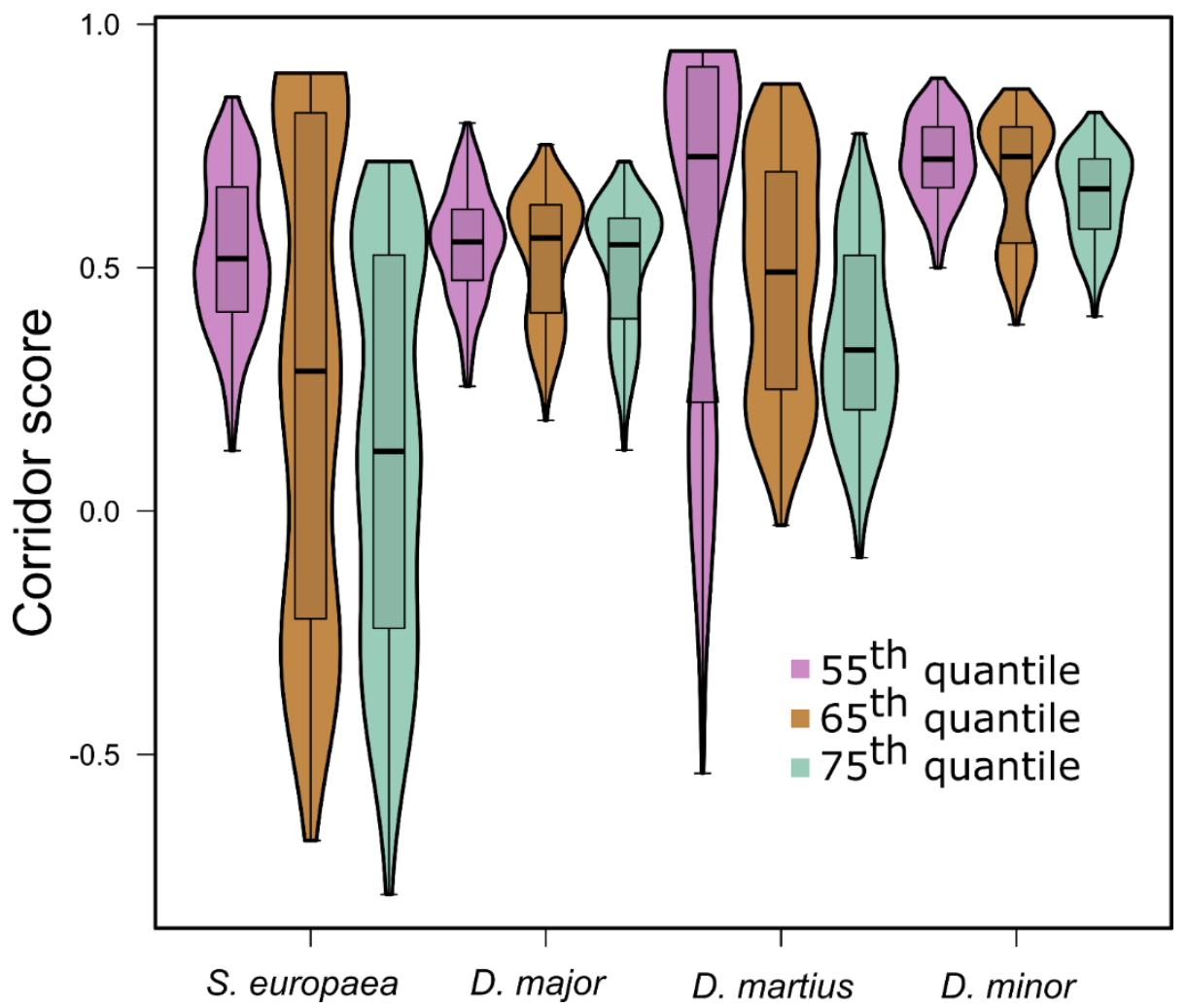

Figure A3. Variation in corridor scores according to species and the quantile used on current values. The corridor score reflects the validity of the corridor location (see Section 2). The graph shows a combination of boxplots and violin plots representing quantile and kernel density for 100 comparisons of random draws from species validation points for the three landscape connectivity approaches.

Appendix G. Supplementary Indices to Validate the Accuracy of Corridor Locations

(A)

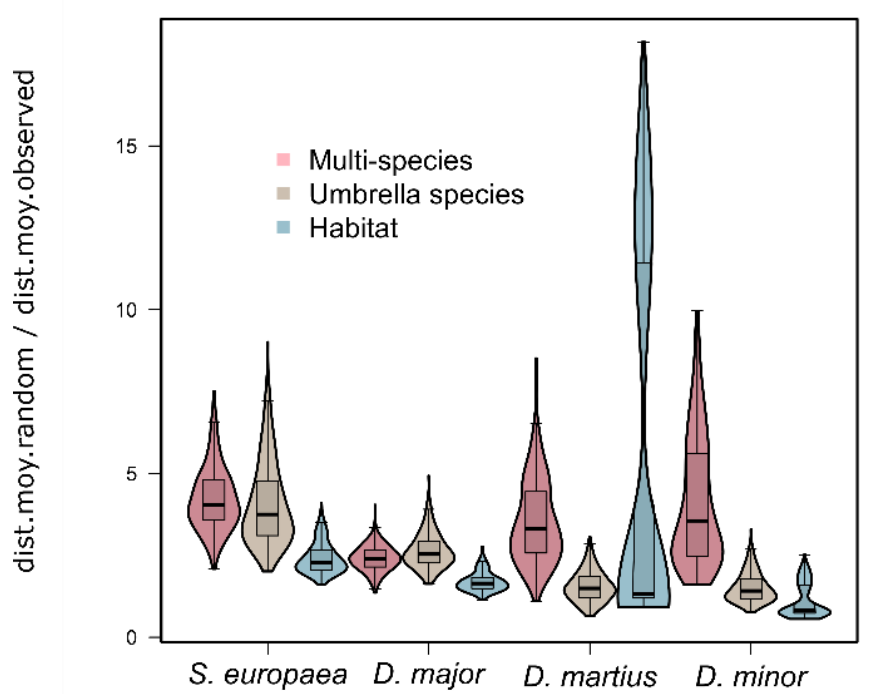

Figure A4. Cont. 
(B)

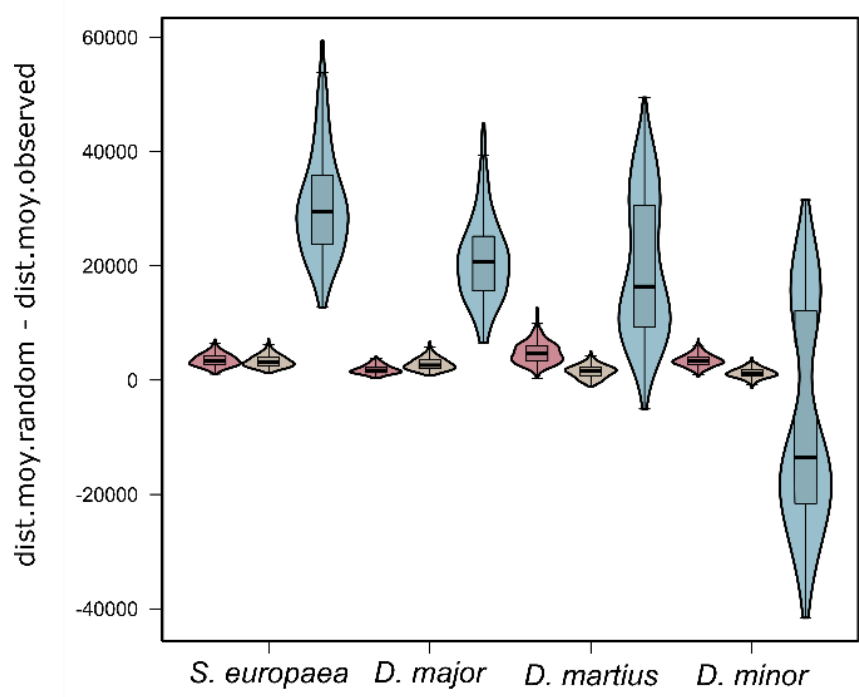

Figure A4. Supplementary indices to validate the accuracy of corridor locations. The first index (A), based on a ratio, shows results consistent with the corridor score, contrary to the second index (B), which is based on a difference. The distribution of matrix resistance values is less flat-tailed (first quartile, median and third quartile were respectively 1, 300 and 700) for the habitat approach than for the umbrella and the multispecies approaches (first, median and third quartiles were respectively 1, 3 and 29, for both approaches). This difference means that the distance between two random pixels had more chance of being greater with the habitat approach than with the other approaches. Contrary to the second index (B), the corridor score formula (Section 2) accounts for this bias and makes it possible to compare different distributions of matrix resistance values.

\section{References}

1. Tucker, M.A.; Böhning-Gaese, K.; Fagan, W.F.; Fryxell, J.M.; Van Moorter, B.; Alberts, S.C.; Ali, A.H.; Allen, A.M.; Attias, N.; Avgar, T.; et al. Moving in the Anthropocene: Global reductions in terrestrial mammalian movements. Science 2018, 359, 466-469. [CrossRef] [PubMed]

2. Hanski, I. Metapopulation dynamics. Nature 1998, 396, 41-49. [CrossRef]

3. Vellend, M. Conceptual synthesis in community ecology. Q. Rev. Biol. 2010, 85, 183-206. [CrossRef]

4. Taylor, P.D.; Fahrig, L.; Henein, K.; Merriam, G. Connectivity is a vital element of landscape structure. Oikos 1993, 68, 571-573. [CrossRef]

5. Gilbert-Norton, L.; Wilson, R.; Stevens, J.R.; Beard, K.H. A meta-analytic review of corridor, effectiveness. Conserv. Biol. 2010, 24, 660-668. [CrossRef] [PubMed]

6. Resasco, J. Meta-analysis on a decade of testing corridor efficacy: What new have we learned? Curr. Landsc. Ecol. Rep. 2019, 4, 61-69. [CrossRef]

7. McRae, B.H.; Dickson, B.G.; Keitt, T.H.; Shah, V.B. Using circuit theory to model connectivity in ecology, evolution, and conservation. Ecology 2008, 89, 2712-2724. [CrossRef]

8. Foltête, J.C.; Clauzel, C.; Vuidel, G. A software tool dedicated to the modelling of landscape networks. Environ. Model. Softw. 2012, 38, 316-327. [CrossRef]

9. Saura, S.; Torne, J. Conefor Sensinode 2.2: A software package for quantifying the importance of habitat patches for landscape connectivity. Environ. Model. Softw. 2009, 24, 135-139. [CrossRef]

10. Avon, C.; Bergès, L. Prioritization of habitat patches for landscape connectivity conservation differs between least-cost and resistance distances. Landsc. Ecol. 2016, 31, 1551-1565. [CrossRef]

11. Keeley, A.T.; Beier, P.; Gagnon, J.W. Estimating landscape resistance from habitat suitability: Effects of data source and nonlinearities. Landsc. Ecol. 2016, 31, 2151-2162. [CrossRef]

12. Meurant, M.; Gonzalez, A.; Doxa, A.; Albert, C.H. Selecting surrogate species for connectivity conservation. Biol. Conserv. 2018, 227, 326-334. [CrossRef]

13. Forman, R.T. Some general principles of landscape and regional ecology. Some general principles of landscape and regional. Landsc. Ecol. 1995, 10, 133-142. [CrossRef]

14. Santini, L.; Saura, S.; Rondinini, C. A composite network approach for assessing multi-species connectivity: An application to road defragmentation prioritisation. PLoS ONE 2016, 11, e0164794. [CrossRef] 
15. Albert, C.H.; Rayfield, B.; Dumitru, M.; Gonzalez, A. Applying network theory to prioritize multispecies habitat networks that are robust to climate and land-use change. Conserv. Biol. 2017, 31, 1383-1396. [CrossRef]

16. Mimet, A.; Clauzel, C.; Foltête, J.C. Locating wildlife crossings for multispecies connectivity across linear infrastructures. Landsc. Ecol. 2016, 31, 1955-1973. [CrossRef]

17. Sahraoui, Y.; Foltête, J.C.; Clauzel, C. A multi-species approach for assessing the impact of land-cover changes on landscape connectivity. Landsc. Ecol. 2017, 32, 1819-1835. [CrossRef]

18. Tannier, C.; Foltête, J.C.; Girardet, X. Assessing the capacity of different urban forms to preserve the connectivity of ecological habitats. Landsc. Urban Plan. 2012, 105, 128-139. [CrossRef]

19. Petsas, P.; Tsavdaridou, A.I.; Mazaris, A.D. A multispecies approach for assessing landscape connectivity in data-poor regions. Landsc. Ecol. 2020, 35, 561-576. [CrossRef]

20. Fleishman, E.; Murphy, D.D.; Brussard, P.F. A new method for selection of umbrella species for conservation planning. Ecol. Appl. 2000, 10, 569-579. [CrossRef]

21. Calabrese, J.M.; Fagan, W.F. A comparison-shopper's guide to connectivity metrics. Front. Ecol. Environ. 2004, 2, 529-536. [CrossRef]

22. Dickson, B.G.; Albano, C.M.; Anantharaman, R.; Beier, P.; Fargione, J.; Graves, T.A.; Gray, M.E.; Hall, K.R.; Lawler, J.J.; Leonard, P.; et al. Circuit-theory applications to connectivity science and conservation. Conserv. Biol. 2019, 33, 239-249. [CrossRef]

23. Wade, A.A.; McKelvey, K.S.; Schwartz, M.K. Resistance-Surface-Based Wildlife Conservation Connectivity Modeling, Summary of Efforts in the United States and Guide for Practitioners; General Technical Report. RMRS-GTR-333; Department of Agriculture, Forest Service, Rocky Mountain Research Station: Fort Collins, CO, USA, 2015; p. 93.

24. Koen, E.L.; Bowman, J.; Sadowski, C.; Walpole, A.A. Landscape connectivity for wildlife: Development and validation of multispecies linkage maps. Methods. Ecol. Evol. 2014, 5, 626-633. [CrossRef]

25. Coulon, A.; Aben, J.; Palmer, S.C.F.; Stevens, V.M.; Callens, T.; Strubbe, D.; Lens, L.; Matthysen, E.; Baguette, M.; Travis, J. A stochastic movement simulator improves estimates of landscape connectivity. Ecology 2015, 96, 2203-2213. [CrossRef]

26. Pinaud, D.; Claireau, F.; Leuchtmann, M.; Kerbiriou, C. Modelling landscape connectivity for greater horseshoe bat using an empirical quantification of resistance. J. Appl. Ecol. 2018, 55, 2600-2611. [CrossRef]

27. Zeller, K.A.; Jennings, M.K.; Vickers, T.W.; Ernest, H.B.; Cushman, S.A.; Boyce, W.M. Are all data types and connectivity models created equal? Validating common connectivity approaches with dispersal data. Divers. Distrib. 2018, 24, 868-879. [CrossRef]

28. Finch, D.; Corbacho, D.P.; Schofield, H.; Davison, S.; Wright, P.G.; Broughton, R.K.; Mathews, F. Modelling the functional connectivity of landscapes for greater horseshoe bats Rhinolophus ferrumequinum at a local scale. Landsc. Ecol. 2020, 35, 577-589. [CrossRef]

29. Foltête, J.-C.; Savary, P.; Clauzel, C.; Bourgeois, M.; Girardet, X.; Sahraoui, Y.; Vuidel, G.; Garnier, S. Coupling landscape graph modeling and biological data: A review. Landsc. Ecol. 2020, 35, 1035-1052. [CrossRef]

30. Fielding, A.H.; Bell, J.F. A review of methods for the assessment of prediction errors in conservation presence/absence models. Environ. Conserv. 1997, 24, 38-49. [CrossRef]

31. Adriaensen, F.; Chardon, J.P.; De Blust, G.; Swinnen, E.; Villalba, S.; Gulinck, H.; Matthysen, E. The application of 'leastcost'modelling as a functional landscape model. Landsc. Urban Plan. 2003, 64, 233-247. [CrossRef]

32. Kotaka, N.; Matsuoka, S. Secondary users of Great Spotted Woodpecker (Dendrocopos major) nest cavities in urban and suburban forests in Sapporo City, northern Japan. Ornithol. Sci. 2002, 1, 117-122. [CrossRef]

33. Verbeylen, G.; De Bruyn, L.; Adriaensen, F.; Matthysen, E. Does matrix resistance influence Red squirrel (Sciurus vulgaris L. 1758) distribution in an urban landscape? Landsc. Ecol. 2003, 18, 791-805. [CrossRef]

34. Phillips, S.J.; Anderson, R.P.; Schapire, R.E. Maximum entropy modeling of species geographic distributions. Ecol. Model 2006, 190, 231-259. [CrossRef]

35. Elith, J.; Leathwick, J.R. Species distribution models: Ecological explanation and prediction across space and time. Annu. Rev. Ecol. Evol. Sys. 2009, 40, 677-697. [CrossRef]

36. Duflot, R.; Avon, C.; Roche, P.; Bergès, L. Combining habitat suitability models and spatial graphs for more effective landscape conservation planning, An applied methodological framework and a species case study. J. Nat. Conserv. 2018, 46, 38-47. [CrossRef]

37. Dilts, T.E.; Weisberg, P.J.; Leitner, P.; Matocq, M.D.; Inman, R.D.; Nussear, K.E.; Esque, T.C. Multiscale connectivity and graph theory highlight critical areas for conservation under climate change. Ecol. Appl. 2016, 26, 1223-1237. [CrossRef]

38. Tarabon, S.; Bergès, L.; Dutoit, T.; Isselin-Nondedeu, F. Maximizing habitat connectivity in the mitigation hierarchy. A case study on three terrestrial mammals in an urban environment. J. Environ. Manag. 2019, 243, 340-349. [CrossRef]

39. Roberge, J.M.; Angelstam, P.E.R. Usefulness of the umbrella species concept as a conservation tool. Conserv. Biol. 2004, 18, 76-85. [CrossRef]

40. Carroll, C.; Noss, R.F.; Paquet, P.C. Carnivores as focal species for conservation planning in the Rocky Mountain region. Ecol. Appl. 2001, 11, 961-980. [CrossRef]

41. Gil-Tena, A.; Brotons, L.; Fortin, M.J.; Burel, F.; Saura, S. Assessing the role of landscape connectivity in recent woodpecker range expansion in Mediterranean Europe: Forest management implications. Eur. J. For. Res. 2013, 132, 181-194. [CrossRef]

42. Lõhmus, A.; Nellis, R.; Pullerits, M.; Leivits, M. The potential for long-term sustainability in seminatural forestry: A broad perspective based on woodpecker populations. Environ. Manag. 2016, 57, 558-571. [CrossRef] [PubMed] 
43. Diniz, M.F.; Machado, R.B.; Bispo, A.A.; Júnior, P.D.M. Can we face different types of storms under the same umbrella? Efficiency and consistency of connectivity umbrellas across different patchy landscape patterns. Landsc. Ecol. 2018, 33, 1911-1923. [CrossRef]

44. Poli, C.; Hightower, J.; Fletcher, R.J. Validating network connectivity with observed movement in experimental landscapes undergoing habitat destruction. J. Appl. Ecol. 2020, 57, 1426-1437. [CrossRef]

45. Osipova, L.; Okello, M.M.; Njumbi, S.J.; Ngene, S.; Western, D.; Hayward, M.W.; Balkenhol, N. Validating movement corridors for African elephants predicted from resistance-based landscape connectivity models. Landsc. Ecol. 2019, 34, 865-878. [CrossRef]

46. Driezen, K.; Adriaensen, F.; Rondinini, C.; Doncaster, C.P.; Matthysen, E. Evaluating least-cost model predictions with empirical dispersal data: A case-study using radiotracking data of hedgehogs (Erinaceus europaeus). Ecol. Model 2007, 209, 314-322. [CrossRef]

47. Balbi, M.; Croci, S.; Petit, E.J.; Butet, A.; Georges, R.; Madec, L.; Caudal, J.-P.; Ernoult, A. Least-cost path analysis for urban greenways planning: A test with moths and birds across two habitats and two cities. J. Appl. Ecol. 2020, 58, 632-643. [CrossRef]

48. Laliberté, J.; St-Laurent, M.H. Validation of functional connectivity modeling: The Achilles' heel of landscape connectivity mapping. Landsc. Urban Plan. 2020, 202, 103878. [CrossRef]

49. Cerqueira, R.C.; Leonard, P.B.; da Silva, L.G.; Bager, A.; Clevenger, A.P.; Jaeger, J.A.G.; Grilo, C. Potential movement corridors and high road-kill likelihood do not spatially coincide for felids in Brazil: Implications for road mitigation. Environ. Manag. 2021, 67, 412-423. [CrossRef]

50. Robertson, E.P.; Fletcher, R.J.; Cattau, C.E.; Udell, B.J.; Reichert, B.E.; Austin, J.D.; Valle, D. Isolating the roles of movement and reproduction on effective connectivity alters conservation priorities for an endangered bird. Proc. Natl. Acad. Sci. USA 2018, 115, 8591-8596. [CrossRef]

51. Fletcher, R.J., Jr.; Sefair, J.A.; Wang, C.; Poli, C.L.; Smith, T.A.H.; Bruna, E.M.; Holt, R.D.; Barfield, M.; Marx, A.J.; Acevedo, M.A. Towards a unified framework for connectivity that disentangles movement and mortality in space and time. Ecol. Lett. 2019, 22, 1680-1689. [CrossRef]

52. Jeltsch, F.; Bonte, D.; Pe'Er, G.; Reineking, B.; Leimgruber, P.; Balkenhol, N.; Schröder, B.; Buchmann, C.M.; Mueller, T.; Blaum, N.; et al. Integrating movement ecology with biodiversity research-exploring new avenues to address spatiotemporal biodiversity dynamics. Mov. Ecol. 2013, 1, 1-13. [CrossRef]

53. Kramer-Schadt, S.; Niedballa, J.; Pilgrim, J.D.; Schröder, B.; Lindenborn, J.; Reinfelder, V.; Stillfried, M.; Heckmann, I.; Scharf, A.K.; Augeri, D.M.; et al. The importance of correcting for sampling bias in MaxEnt species distribution models. Divers. Distrib. 2013, 19, 1366-1379. [CrossRef]

54. Lislevand, T.; Figuerola, J.; Székely, T. Avian body sizes in relation to fecundity, mating system, display behavior, and resource sharing: Ecological Archives E088-096. Ecology 2007, 88, 1605. [CrossRef]

55. Sutherland, G.D.; Harestad, A.S.; Price, K.; Lertzman, K.P. Scaling of natal dispersal distances in terrestrial birds and mammals. Conserv. Ecol. 2000, 4, 16. [CrossRef]

56. Bowman, J. Is dispersal distance of birds proportional to territory size? Can. J. Zool. 2003, 81, 195-202. [CrossRef]

57. Boussard, H.; Baudry, J. Chlo: A Software for Landscape Pattern Analysis. 2014. Available online: https://www6.rennes.inrae.fr/ bagap/PRODUCTIONS/Logiciels (accessed on 29 November 2021).

58. Dunning, J.B.; Danielson, B.J.; Pulliam, H.R. Ecological processes that affect populations in complex landscapes. Oikos 1992, 169, 175. [CrossRef]

59. Gillies, C.S.; Clair, C.C.S. Functional responses in habitat selection by tropical birds moving through fragmented forest. J. Appl. Ecol. 2010, 47, 182-190. [CrossRef]

60. Weissteiner, C.J.; Ickerott, M.; Ott, H.; Probeck, M.; Ramminger, G.; Clerici, N.; Dufourmont, H.; De Sousa, A.M.R. Europe's green arteries-A continental dataset of riparian zones. Remote Sens. 2016, 8, 925. [CrossRef]

61. Kosiński, Z.; Pluta, M.; Ulanowska, A.; Walczak, Ł.; Winiecki, A.; Zarębski, M. Do increases in the availability of standing dead trees affect the abundance, nest-site use, and niche partitioning of great spotted and middle spotted woodpeckers in riverine forests? Biodivers. Conserv. 2018, 27, 123-145. [CrossRef]

62. Myczko, Ł.; Rosin, Z.M.; Skórka, P.; Tryjanowski, P. Urbanization level and woodland size are major drivers of woodpecker species richness and abundance. PLoS ONE 2014, 9, e94218. [CrossRef]

63. Rassati, G. Responsiveness to acoustic stimulation, distribution and habitat preferences of the Lesser Spotted Woodpecker, Dendrocopos minor, in Friuli-Venezia Giulia (North-eastern Italy). Riv. Ital. Ornitol. 2015, 85, 51-60. [CrossRef]

64. Liu, C.; White, M.; Newell, G. Selecting thresholds for the prediction of species occurrence with presence-only data. J. Biogeogr. 2013, 40, 778-789. [CrossRef] 